\title{
NOTAS
}

\section{Los Móviles del Crimen Impalas y Peregrinos en el desierto de Bolaño}

\author{
Mario Gomes \\ Universität der Künste (Berlín). Correo electrónico: m.gomes@udk-berlin.de
}

\section{PAPer towns}

La indagación filológica de fondo, según Bolaño, equivale al trabajo de campo. $\mathrm{Su}$ destino, por excelencia, es Santa Teresa, ciudad-archivo en la que se cruzan los caminos de quienes siguen las huellas de escritores desaparecidos. Es en Santa Teresa que el cuarteto de detectives salvajes halla la primera pista verdaderamente concluyente en su búsqueda por la poetisa Cesárea Tinajero, y es ahí también que los filólogos no menos salvajes de 2666 esperan encontrar al escritor alemán Benno von Archimboldi.

La única forma de llegar a Santa Teresa es en automóvil. Los detectives viscerrealistas viajan desde el D. F., los archimboldianos en un coche alquilado en Hermosillo. Al llegar, la ciudad ni siquiera existe. Lo que hay es un espacio indefinido que se asemeja a "un enorme campamento de gitanos o de refugiados dispuestos a ponerse en marcha a la más mínima señal" (Bolaño 2010: 149), tan caótico que hace reír (cf. Bolaño 2010: 150). Santa Teresa es una ciudad en constante edificación. Se va armando mientras proceden las búsquedas filológicas, literalmente sobre la marcha. Su topografía volátil, el trazado de sus calles, se forma a la medida que se avanza en la narración. De hecho, la ciudad es pura narración, una urbe literaria que se construye tal cual el Atlas de Michel Serres (1994: 103), lugar por lugar, palabra por palabra. En Santa Teresa, mapa, texto y territorio son indisociables. El nexo que los une no es de relación, sino de identidad. Reducirlo a una fórmula, como "[e] 1 mapa es al territorio lo que la ficción es a la realidad" (De los Ríos 2008: 238), equivale a ignorar uno de los principios de base de la literatura de Bolaño, según el cual el texto-mapa no se limita a una existencia recluida en el ámbito de la ficción sino que genera realidad.

La "escenografía de papel” (Bolaño 2010: 179) que es Santa Teresa no tiene referente en el "mundo real". Por el contrario, su status -tal como el de muchos otros topónimos bolañianos- es el de un paper town, que es como en la cartografía se designan los topónimos ficticios que se añaden a un mapa con la finalidad de salva- 
guardarlo de plagios. Quien copie un mapa ilícitamente, además de la información correcta, copiará también a los paper towns y calles trampa, quedando el plagio fácil de demostrar. Si bien el propósito del paper town es proteger los derechos de autor de un mapa, hay varios casos documentados de topónimos ficticios que han pasado del mapa a la realidad, invirtiendo la relación entre original y copia ${ }^{1}$. Algo no del todo disímil se verifica con los mapas de Bolaño que han inspirado varios proyectos de investigación -académica y periodística- dedicados a mapear el periplo de los detectives salvajes por México. Existen foto-reportajes en que se siguen los rastros de los viscerrealistas por el D. F., callejeros con rutas turísticas por los bares preferidos de Arturo Belano y Ulises Lima, o rutas en google maps con la supuesta ruta de los detectives por Sonora. El problema de base que conlleva el ejercicio de trazar identidades entre el mundo literario, como lo concibe Bolaño, y la realidad extra-literaria se hacen evidentes, por ejemplo, a la hora de localizar los paper towns bolañianos en el Desierto de Sonora. Como son varios los topónimos ficticios, para transferir la ruta de los Detectives Salvajes al mapa, no queda otra posibilidad que la de hacer trampa: inventar coordinadas para Villaviciosa, hacer de Santa Teresa un sinónimo de Ciudad Juárez o hacer de cuenta que el pueblo de El Cubo y Cubabi son idénticos ${ }^{2}$.

El intento de forzar la transferencia del mapa literario al mapa geográfico es tan solo un ejemplo que ilustra las dificultades que advienen de la ilusión de que la topografía en la literatura de Bolaño se basa exclusivamente en referentes "reales". Así, para que el juego de correspondencias funcione, se crean nexos de identidad donde estos no existen. Se decreta Santa Teresa como variante literaria de Ciudad Juárez o se establece que el Bar Quito "en realidad” se llama Bar La Habana, siempre tomando el mundo "real" o "empírico" como matriz, quedando el universo literario relegado al rol de copia, una distinción que, además de simplista, no le hace mucha justicia a la literatura, mucho menos a la literatura tal como la concibe Bolaño. En realidad -y hay énfasis en esta expresión-, Santa Teresa no es Ciudad Juárez, ni tampoco su "fiel trasunto" (cf. Echevarría 2010: 1123), sino simplemente una ciudad diferente. Autónoma. Literaria. Aunque mucho de lo que ahí pasa remita a sucesos que se conocen de Ciudad Juárez, y aunque incluso se pueda establecer que los crímenes de Santa Teresa se basan o se inspiran en los hechos de Juárez, lo que verdaderamente cuenta es la autonomía de Santa Teresa. No por casualidad, en la geografía Bolañiana, con sus pueblos que "parecen espejismos” (Bolaño 2014: 574), ambas ciudades coexisten: "Ciudad Juárez, en Chihuahua" (Bolaño 2010: 486) y "Santa Teresa, Sonora" (Bolaño 2010: 770).

Más que una copia de un referente del "mundo real", Santa Teresa es un conglomerado de signos, en el que se hallan trazos y trazados - eso sí- que remiten a Juárez. Hay un Hotel llamado Juárez, ubicado en una calle con el mismo nombre, en la que lo único digno de contemplar, más allá de sombras y basura, parece ser el tráfico (Bolaño 2014: 569). El dato no deja de ser significativo, puesto que es a fuerza de tráfico que el entramado de calles que es Santa Teresa se constituye. Sin automóviles la ciudad no existiría. Más que mero accesorio escénico, el automóvil

Un ejemplo conocido es el de Agloe, en el estado de Nueva York, que de localidad ficticia se convirtió en topónimo «real» (cf. Jacobs 2014).

Cf. Habash (2014) que intenta reconstituir el recorrido de Los Detectives Salvajes en google maps, y también el proyecto fotográfico de José Luis Vidal Coy (2015) o la Ruta Bolaño de Mariana Castillo (2014). 
configura espacio y texto, instaurando lo que Charles Grivel (2005: 61) apellida una "escritura automovilística", en la que el automóvil es fuerza motriz de la escritura.

Entre los incontables automóviles que surgen a lo largo de Los Detectives Salvajes y 2666 -obras en las que se concentrará el presente estudio- hay dos en particular que se asumen como claves para una lectura poetológica del coche en cuanto método de escritura automovilística. Uno es blanco, el otro, negro.

\section{Las ventanas del Impala}

En Los Detectives Salvajes, el viaje al Norte de México se hace en un Impala blanco $^{3}$, reluciente de tan nuevo, que el cuarteto de aventureros pide prestado -un poco a malas, es cierto- al arquitecto Quim Font, para escapar del cerco montado por Alberto, el proxeneta de Lupe. La función primera del Impala es entonces crear una

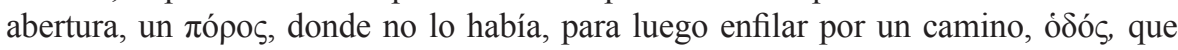
pronto se convertirá en método: $\mu \varepsilon \tau$ ó-óóó. El recorrido del Impala va de la aporía -la ausencia de un $\pi$ ópos- al método; de la casa sitiada al espacio abierto del desierto. Es allí que el Impala -más que transformarse en símbolo erótico, de libertad o de iniciación- se asume como lo que verdaderamente es: vehículo metódico y medio de transporte. Es el Impala que, en su recorrido por el desierto, cartografía la Sonora de Bolaño y transporta los detectives más allá del desierto, al texto en toda su materialidad.

Mientras el Impala gira sobre un asfalto -que pronto se disuelve en casquijo, terracería, arena-, el texto se arma, carretera y papel se confunden. Se asiste a la sincronización de conducción y escritura, de automóvil e instrumento de escritura. El Impala se asume, así, como un complejo dispositivo de configuración de texto: una cápsula que encierra en su interior piloto y copiloto -Ulises Lima y Arturo Belano-con el duo de anotadores-copuladores en el banco de atrás: García Madero y Lupe. En esta disposición se concentra toda una poetología. Belano, alter ego de Bolaño -a quien Juan Villoro (2006: 77ss.) se refiere como "el copiloto del Impala"-, entrega el volante a Lima y la anotación a los que van sentados en el banco de atrás. El autor o, en su defecto, su representante, no conduce ni escribe. Se deja llevar, encerrado en la cápsula automóvil que, mientras constituye el espacio literario, parece ganar vida propia, separándose de quienes siguen en su interior. De forma virtualmente automática, el Impala "circula por las calles del centro de la ciudad" (Bolaño 2014: 568) o "se abr[e] paso en la oscuridad" (Bolaño 2014: 564), denotando autonomía e incluso personalidad, colocado virtualmente al mismo nivel de los demás personajes: "Lima estacionó cerca de una plaza cercana y me dijo que fuera a la biblioteca. Él se quedaba con Lupe y el Impala, por si aparecía Alberto y había que salir huyendo" (Bolaño 2014: 588).

Si por un lado el Impala, sujeto e instrumento de la escritura, funciona encapsulando a los cuatro aventureros, ${ }^{4}$ a la vez se exterioriza y automatiza. Esto no significa que

García Madero y Quim Font coinciden en que se trata de un Ford Impala, modelo inexistente fuera del mundo de Los Detectives Salvajes, donde "Impala" es un modelo de Chevrolet. Sin embargo, tal como Santa Teresa no es Ciudad Juárez, tampoco el Impala de Bolaño es un Chevrolet, no quedando otra alternativa que aceptarlo como equivalente automóvil de los paper towns.

Hay bastantes semejanzas entre el Impala de Bolaño (aunque no sea un Chevrolet) y el Chevrolet del heterónimo modernista de Fernando Pessoa, Álvaro de Campos (1985), en el poema Ao volante do Chevrolet pela Estrada de Sintra. A semejanza de lo que sucede con el Impala, el Chevrolet de Álvaro de Campos solo se presta a la circulación 
la escritura automovilística se entienda como sinónimo de escritura automática. Más bien se trata de una escritura en la que el coche se asume como configurador espacial y textual, abriendo camino por un espacio que paulatina y alegóricamente se deposita sobre la carrocería, cuyo color "desaparec[e] bajo la capa de polvo del desierto" (Bolaño 2014: 578). Es este sedimento semiótico que el coche transporta hasta el umbral de lo literario, hasta la ventana en punteado al final de la novela, sobre la cual mucho se ha especulado, en absoluto detrimento de otra ventana no menos preponderante: la ventana trasera del Impala que surge en primerísimo plano en el último párrafo de la primera parte de la novela: "Me volví y a través de la ventana trasera vi una sombra en el medio de la calle. En esa sombra, enmarcada por la ventana estrictamente rectangular del Impala se concentraba toda la tristeza del mundo" (Bolaño 2014: 136s.). La ventana trasera no solo enmarca sino que constituye positivamente el espacio narrativo. Lo que se ve a través de ella equivale a lo que se lee. El cuadro se compone semánticamente, la escena se construye a fuerza de palabras, en retrospección. Es precisamente este aspecto retrospectivo que se presta como contrapunto a la ventana en disolución al final de "Los Desiertos de Sonora", que es esencialmente una ventana de proyección. Es a través de ella que el juego de acertijos con el que se entretienen los pasajeros del Impala se proyecta hacia el exterior del texto, donde el juego prosigue, en la experiencia del lector o en el universo paralelo de la literatura secundaria $^{5}$. Por la ventana en disolución se llega -y no es fruto de ninguna hermenéutica, sino un dato empírico- al lado de acá. Se repite, entonces, lo sucedido con Amadeo Salvatierra a la hora de interpretar el poema gráfico Sión de Cesárea Tinajero. En este caso, la proyección de las olas líricas hacia el tiempo-espacio extraliterario es instantánea:

Por un momento mi cabeza, les aseguro, era como un mar embravecido y no oí lo que los muchachos decían [...]. Y entonces, después de beber mi tequila, llené mi copa otra vez y llené la de ellos y les dije que brindáramos por Cesárea y vi sus ojos, qué contentos estaban los pinches muchachos, y los tres brindamos mientras nuestro barquito era zarandeado por la galerna (Bolaño 2014: 401).

En la proyección del barco y de las olas hacia la sala de Amadeo Salvatierra, la matriz realidad/mimésis se invierte. Ya no es la literatura la que imita al "mundo real", sino la "realidad" que asimila los tropos del texto. El texto desborda y genera realidad. Es esta proyección que se repite en el final de la novela, en una implosión metonímica, en la que el Impala, el coche entero, se transforma en esa misma ventana que el vehículo, otrora blanco, transpone al final de libro.

\section{Peregrino negro}

Tras más de una década, en una calle del D. F., Quim Font cree avistar a su Impala, "gastado por los años, con abolladuras en los guardabarros y en las puertas, con la pintura descascarada", circulando "muy lentamente, a vuelta de rueda" (Bolaño 2014:

y, por ende, a la escritura, al encerrar al anotador -en este caso al sujeto lírico- en su interior.

5 Lo sugiere el mismo Bolaño (2006b: 204), cuando dice que la novela se puede "leer como una agonía", pero "[t] ambién se puede leer como un juego". 
382) y sin conductor. Se trata, por supuesto, de una alucinación, ni que sea ya por el hecho de que el Impala, tras haber transpuesto la ventana en punteado, se encuentra -por ponerlo de alguna forma- en otro mundo. Pero Quim Font no es el único en avistar al Impala fantasma. Hay, también, quien cree reconocerlo en 2666. El crítico literario Felipe Ríos Baeza (2010: 248), por ejemplo, sugiere que el misterioso coche negro que "realiza rondines como anuncio de las muertes que vendrán y de la fatalidad del futuro" no es nada más ni nada menos que el Impala de Los Detectives Salvajes, pintado de negro y con Arturo Belano al mando. Evidentemente, se trata de un espejismo más, puesto que, entre los variadísimos coches que aparecen en 2666, no surge ni siquiera un único Impala. Hay coches negros, eso sí, pero su función no consiste, seguramente, en anunciar las muertes por venir, como sugiere Ríos. Leer el coche negro como mero presagio de muerte equivale a reducirlo a guiño proléptico, a forzar su integración simbólica en una linealidad teleológica. Sin embargo, en términos estrictamente semióticos, el coche negro no es del todo un símbolo, ni mucho menos un ícono. Es, acaso, un indicio, una pista, quizás la única pista realmente prometedora para resolver al menos una parte de los crímenes de Santa Teresa. Varios son los testigos que relacionan un coche negro con las desapariciones. De entre las hipótesis que se barajan, el modelo que los testigos mencionan más a menudo es un Peregrino: “[A] lgunas amigas dijeron haber visto subir a Mónica a un coche negro, con las ventanas ahumadas, tal vez un Peregrino o un Master Road o un Silencioso" (Bolaño 2010: 516); "dos compañeras de Andrea [...] la vieron dirigirse a un coche negro, probablemente un Peregrino o un Spirit" (Bolaño 2010: 490); "Aurora Muñoz se subió a un Peregrino de color negro" (Bolaño 2010: 576). La conclusión de los investigadores es obvia: hay que buscar un Peregrino de color negro (cf. Bolaño 2010: 660).

Aparte del coche, el único sospechoso digno de mención parece ser un alemán: Klaus Haas, sobrino-sosia del escritor Benno von Archimboldi, con el que se confunde no solo en la apariencia física. De hecho, el grado de similitud es tal que hasta un crítico tan sobrio como Peter Elmore (2008: 269) termina por amalgamar los nombres, creando un híbrido "Klaus von Haas". El lapsus lo dice todo: Archimboldi, autor literario, y Haas, presunto autor de una serie de feminicidios, son dos caras de la misma moneda. Aunque luego no haya, como explica Elmore (2008: 275), "indicios narratológicos claros" que permitan imputar los crímenes al alemán, no hay tampoco cómo disociar la culpa de Haas de la culpa de su tío. En este caso, lo que cuenta en términos de economía literaria no es ni el nexo de causalidad, ni una noción de verosimilitud anclada en el "mundo real", sino la carga poetológica de la matriz de los crímenes de Santa Teresa. Ésta la traza Benno von Archimboldi, cuando, poco después de la Segunda Guerra Mundial, estrangula a un tal de Leo Sammer que se jacta de ser el responsable de la muerte de docenas de judíos:

Una mañana encontraron el cadáver de Sammer a medio camino entre la tienda de campana y las letrinas. Alguien lo había estrangulado. Los norteamericanos interrogaron a unos diez prisioneros, entre ellos Reiter, que dijo no haber oído nada fuera de lo común aquella noche, y luego se llevaron el cuerpo y lo enterraron en la fosa común del cementerio de Ansbach. (Bolaño 2010: 960)

Este asesinato se produce, al igual que la mayor parte de los asesinatos de Santa Teresa, por estrangulamiento, prefigurando así las atrocidades de la Parte de los Crímenes. El asesinato perpetrado por Archimboldi constituye la matriz que se 
replica en los asesinatos de Santa Teresa, donde cada fosa común remite a la fosa común de Ansbach. Que luego la mayor parte de los asesinatos de Santa Teresa queden por aclarar, resulta irrelevante. Lo que sí importa es que el asesinato-tipo lo ejecuta el escritor Benno von Archimboldi, por lo que una vez más -como a menudo sucede en la obra de Bolaño- es un escritor que se encuentra en el origen del mal. Sin embargo, con la proliferación de violencia, el nexo de autoría se evapora. Las víctimas simplemente "brotan" del desierto (Bolaño 2010: 701). Lo que queda es una firma disociada de cualquier autoría y motivación.

Como explica el judicial Ernesto Ortiz Rebolledo, en 2666, "el asesino en serie deja su firma [...], no tiene un móvil, pero tiene una firma", a lo que el presidente municipal protesta: “¿Cómo que no tiene un móvil? ¿Acaso se mueve por impulsos eléctricos?", mientras un tercer personaje, representante de la cámara de comercio de Santa Teresa, parece concordar tanto con el argumento como con la objeción, resaltando que "[e]n esta clase de asuntos hay que examinar muy bien a las palabras" (Bolaño 2010: 589). En esta clase de asuntos, claro está, también la palabra "móvil" se reviste de una intrincada ambivalencia semántica. Tanto puede referirse a un medio de desplazamiento como al "móvil del crimen", es decir a la motivación detrás del asesinato. Suspendido en esta ambivalencia, el móvil del crimen se hace literalmente "automóvil".

La firma ambulante de la muerte se materializa en el Peregrino, caja negra misteriosa. Sobre el modelo, poco se sabe más allá del hecho de que se trata de "un coche de moda entre los jóvenes pudientes" y que "la casi totalidad de la flota de Peregrinos de la ciudad" se encuentra en manos de los hijos de "algunos peces gordos" (Bolaño 2010: 663). Resulta, pues, que hay toda una flota de Peregrinos. Y resulta, también, que justamente cuando los investigadores empiezan a seguir la pista del Peregrino, los peces gordos, molestos, instan a las "autoridades pertinentes [...] que los polis dej[en] de joder" (Bolaño 2010: 663). Por orden superior, la pista del Peregrino se abandona y el coche termina esfumándose en la trama. Aun así, el detective-lector que se rehuse a desistir de esa pista, que tan prometedora parecía, terminará reencontrando al Peregrino, transmutado, es cierto, deambulando subrepticiamente por el texto, surgiendo ya no como modelo de automóvil sino como adjetivo, metamorfoseado en expresiones como "lógica peregrina" (Bolaño 2010: 248), "lugares [...] peregrinos" (285) o "ideas peregrinas" (888), como metáfora de la luna que la vidente Florita Almada llama la "eterna peregrina" (541) o bajo el manto del "peregrinaje", que se depara, no más abrir el libro, en el segundo párrafo de "La parte de los críticos" (15). A su vez, en Los Detectives Salvajes, Cesárea Tinajero, al referirse a un futuro lejano, señala "el año 2600. Dos mil seiscientos y pico", "una fecha tan peregrina" que provoca risa (Bolaño 2014: 596s.). Resonancias como éstas se hallan un poco por toda la obra de Bolaño, en la que se evidencia una peculiar predilección por el campo semántico del "peregrinaje". Para encontrar una semejante concentración del vocablo "peregrino", hay que retroceder hasta el Siglo de Oro, donde el término surge frecuentemente relacionado con la retórica de lo oscuro, característica de la época, en particular en las misceláneas. Antonio de Torquemada (1982: 103), por ejemplo, habla de la diversidad de las "materias subidas y peregrinas", misterios ocultos de la naturaleza, cuyo conocimiento, inaccesible a la mayoría, el autor nunca devela por completo, sino que lo mantiene oculto en un intrincado juego de "sabiduría 
escondida" . Hay, así, una semejanza entre la materia peregrina que queda en la oscuridad y la otra materia peregrina en constante transmutación polisémica que circula secretamente entre líneas. Como observa Ezequiel De Rosso:

En Bolaño el secreto produce sentidos, se desplaza y, por eso mismo, tiene valor narrativo. Se trata de ver al secreto "entre": siempre en circulación, siempre en tránsito; no ubicar su origen o su fin, sino más bien el recorrido que media entre ambos. Se trata $[\ldots]$ de pensar narraciones con "agujeros" que en su desplazamiento definen las formas de la ficción (De Rosso 2002: 137).

Estas formas de desplazamiento subrepticio son determinantes en la obra de Bolaño, y están en la base de una intertextualidad y circularidad que muy comúnmente se agotan en lecturas a la luz de conceptos como el de "neobarroco". Mas allá de señalar fenómenos con tales etiquetas -que conllevan una pesada carga discursiva y mucha rigidez-, interesa explorar el texto en su dinamismo orgánico, concentrando la lectura en el funcionamiento de la circulación sémica. Esta se manifiesta, esencialmente, en dos modalidades: una -y es, por excelencia, el caso del "Peregrino"- es el incremento polisémico, en todo semejante a la "dilación sémica" constatada por Roland Barthes en la obra de Proust, donde el nombre propio se presenta como esencialmente "catalizable": "[S]e lo puede llenar, dilatarlo, colmar los intersticios de su armadura sémica con una infinidad de agregados" (Barthes 2005: 180). La segunda modalidad consiste en la variación de un motivo, en este caso del "coche negro", que reaparece constantemente a lo largo de la obra de Bolaño, no tanto como símbolo sino como reminiscencia sobre ruedas. Así, el coche negro surge en un poema intitulado Bólido, que abre con los versos "El automóvil negro desaparece / en la curva del ser", y concluye locuazmente: "Acariciémonos toda la noche / del ser y de su negro coche" (Bolaño 2006a: 67). En la noche del ser hay siempre un coche, eterno peregrino, vehículo de diseminación, difusor de las tinieblas del ser, un coche fantasmagórico que surge como "eco silencioso" cuando menos se espera, tal como sucede en Amuleto, donde varias réplicas del coche negro circulan, intermitentes, por una de las grandes avenidas del D. F., como arrastradas por la corriente de un infinito río Grijalva:

[A]quel Grijalva que fluía en la noche era, bajo todos los aspectos, un río condenado, por cuya corriente se deslizaban cadáveres o prospectos de cadáveres, automóviles negros que aparecían, desaparecían y volvían a aparecer, los mismos o sus silenciosos ecos enloquecidos, como si el río del infierno fuera circular [...]. (Bolaño 1999: 78)

Esta circulación semiótica es una de las características elementales del entramado novelístico de Bolaño, por el que deambulan coches negros proteicos, en constante transmutación, que, aparezcan donde aparezcan, remiten a los crímenes. En la luna peregrina o en las ideas peregrinas resuena siempre el habitáculo en el que se encierran las víctimas juntamente con sus verdugos, camino a su destino. Evidentemente, la intuición de esta violencia subrepticia requiere de un cierto grado de paranoia. No por casualidad, el primero en intuir la amenaza que presupone el Peregrino negro

Acerca de las "materias peregrinas" y la "retórica del oscuro", cf. Lalomia 2004: 271ss. 
aparcado a pocos metros de la casa es Amalfitano, en pleno surto esquizofrénico. Sin embargo, su certidumbre es tal, que no hesita un momento en poner a su hija a salvo, mandándola de vuelta a Barcelona. Quien lea 2666 con la misma lucidez paranoica -en este caso, una cosa no excluye la otra- de Amalfitano, no dejará de reencontrar la muerte en cada coche negro, en cada Peregrino o en cada uno de los demás coches con los que el Peregrino se confunde: Spirits y Silenciosos, coches con nombres sumamente elocuentes. Quien se fije en el coche, no dejará de reparar en su relación con la muerte, una relación que el propio Bolaño (2007: 157 y 322) formula en dos esbozos de poemas publicados póstumamente: "La muerte es un automóvill". Esa muerte automóvil circula impregnada en las palabras.

\section{OBRAS CITADAS}

Barthes, Roland. 2005. El grado cero de la escritura. Seguido de Nuevos Ensayos Críticos. Trad. Nicolás Rosa. Madrid: Siglo XXI.

Bolaño, Roberto. 2014. Los Detectives Salvajes. 25a ed. Barcelona: Anagrama. , 2010. 2666. $11^{\text {a }}$ ed. Barcelona: Anagrama. 2007. La Universidad Desconocida. Barcelona: Anagrama. 2006a. Los Perros Románticos. Poemas 1980-1998. Barcelona: Acantilado. 2006b. "Acerca de los Detectives Salvajes". En Manzoni, Celina (Ed.). Roberto Bolaño: la escritura como tauromaquia. Buenos Aires: Corregidor. 203-204. , 1999. Amuleto. Barcelona: Anagrama.

Castillo, Mariana. 2014. "Ruta Bolaño". Disponible en https://rutabolanoendf. wordpress.com [último acceso: 05.08.2016].

De los Ríos, Valeria. 2008. "Mapas y Fotografías en la obra de Roberto Bolaño". En Paz Soldán, Edmundo y Faverón Patriau, Gustavo (Eds.). Bolaño Salvaje. Barcelona: Candaya. 237-258.

De Mora, Carmen. 2011. "En Torno a Los Detectives Salvajes de Roberto Bolaño”. América sin nombre 16: 171-180.

De Rosso, Ezequiel. 2002. "Una lectura conjetural. Roberto Bolaño y el relato policial.” Manzoni, Celina (Ed.). Roberto Bolaño: la escritura como tauromaquia. Buenos Aires: Corregidor. 133-143.

Echevarría, Ignacio. 2010. "Nota a la primera edición”. En Bolaño, Roberto. 2666. 11ª ed. Barcelona: Anagrama. 1121-1125.

Elmore, Peter. 2008. "2666: La autoría en el tiempo del límite”. Paz Soldán, Edmundo y Faverón Patriau, Gustavo (Eds.). Bolaño Salvaje. Barcelona: Candaya. 259-292.

Grivel, Charles. 2005. "Voitures écrites, écritures automobilistiques". En Monneyron, Frédéric y Thomas, Joël (Eds.). Automobile et Littérature. Perpiñán: Presses Universitaires de Perpignan. 57-70.

Habash, Gabe. 2014. "A Google Map of the Road Trip in 'The Savage Detectives"'. Disponible en http://publishersweekly.tumblr.com/post/ 84376088676/ [último acceso: 05.08.2016].

Jacobs, Frank. 2014. "Agloe, the Paper Town Stronger than Fiction”. Disponible en http:// bigthink.com/strange-maps/643-agloe-the-paper-town-stronger-than-fiction [último acceso: 05.08 .2016$]$.

Lalomia, Gaetano. 2004. "La 'sabiduría escondida' nelle miscellanee del XVI secolo". En Lachin, Giosuè y Zambon, Francesco (Eds.). Obscuritas. Retorica e poetica dell'Oscuro. Atti del XXIX Convegno Interuniversitario di Bressanone (12-15 luglio 2001). Trento: Università degli Studi di Trento. 271-294.

Ríos Baeza, Felipe A. 2010. “Arturo Belano: El viajero en el tiempo.” En Ríos Baeza, Felipe 
LOS MÓVILES DEL CRIMEN

IMPALAS Y PEREGRINOS EN EL DESIERTO DE BOLAÑO

(Ed.). Roberto Bolaño: Ruptura y violencia en la literatura finisecular. Mexico: Eón. 219-252.

Serres, Michel. 1994. Atlas. París: Julliard.

Torquemada, Antonio de. 1982. Jardin de Flores Curiosas. Ed. Allegra, Giovanni. Madrid: Castalia.

Vidal Coy, José Luis. 2015. “Con los detectives salvajes” [catálogo de exposición]. Disponible en http://estaticoarchivo.carm.es/adjuntos/ DOC24572985656_497_Catalogovidalcoy. pdf [último acceso: 05.08.2016].

Villoro, Juan. 2006. "El copiloto del Impala". En Manzoni, Celina (Ed.). Roberto Bolaño: la escritura como tauromaquia. Buenos Aires: Corregidor. 77-80. 
